\title{
Physiologically-Based Pharmacokinetic and Pharmacodynamic Modeling for the Inhibition of Acetylcholinesterase by Acotiamide, A Novel Gastroprokinetic Agent for the Treatment of Functional Dyspepsia, in Rat Stomach
}

\author{
Kazuyoshi Yoshii' • Minami likura' • Masamichi Hirayama' • Ryoko Toda' • Yoshihiro Kawabata'
}

Received: 20 February 2015 / Accepted: 31 August 2015 / Published online: 9 September 2015

(C) The Author(s) 2015. This article is published with open access at Springerlink.com

\begin{abstract}
Purpose Acotiamide, a gastroprokinetic agent used to treat functional dyspepsia, is transported to at least two compartments in rat stomach. However, the role of these stomach compartments in pharmacokinetics and pharmacodynamics of acotiamide remains unclear. Thus, the purpose of this study was to elucidate the relationship of the blood and stomach concentration of acotiamide with its inhibitory effect on acetylcholinesterase (AChE).
\end{abstract}

Methods Concentration profiles of acotiamide and acetylcholine (ACh) were determined after intravenous administration to rats and analyzed by physiologically-based pharmacokinetic and pharmacodynamic (PBPK/PD) model containing vascular space, precursor pool and deep pool of stomach.

Results Acotiamide was eliminated from the blood and stomach in a biexponential manner. Our PBPK/PD model estimated that acotiamide concentration in the precursor pool exceeded $2 \mu \mathrm{M}$ at approximately $2 \mathrm{~h}$ after administration. Acotiamide inhibited AChE activity in vitro with a $50 \%$ inhibitory concentration of $1.79 \mu \mathrm{M}$. ACh reached the maximum concentration at $2 \mathrm{~h}$ after administration.

Conclusions Our PBPK model well described the profile of acotiamide and ACh concentration in the stomach in the assumption that acotiamide was distributed by carrier mediated process and inhibited AChE in the precursor pool of stomach. Thus, Acotiamide in the precursor pool plays an important role for producing the pharmacological action.

KEY WORDS acetylcholine - acetylcholinesterase . functional dyspepsia · pharmacodynamics · pharmacokinetics

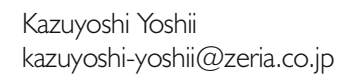

Central Research Laboratories, Zeria Pharmaceutical Co., Ltd, 25।2-I Numagami, Oshikiri, Kumagaya, Saitama 360-0 I I I, Japan

\author{
ABBREVIATIONS \\ ACh Acetylcholine \\ AChE Acetylcholinesterase \\ FD Functional dyspepsia \\ PBPK Physiologically-based pharmacokinetic \\ PD Pharmacodynamic
}

\section{INTRODUCTION}

Functional dyspepsia (FD) is a disease of subjective symptoms, including postprandial fullness, early satiation, and epigastric pain, which exhibits no organic abnormalities in the stomach $[1,2]$. Although the pathophysiology of FD is not fully established, gastric dysmotility has been reported as a putative cause of FD. Gastric motility is mainly regulated by the cholinergic system, which is regulated by factors such as acetylcholine (ACh). ACh is released from presynaptic neurons into the synaptic cleft, where it then binds to ACh receptors and either affects gastric motility or is inactivated by acetylcholinesterase (AChE). This relationship suggests that gastric motility might be regulated via the inhibition of AChE activity and that AChE inhibitors might effectively treat patients with FD $[3,4]$.

Acotiamide was the first drug to receive approval for use in treating FD [5-7]. This compound inhibited AChE and enhanced the gastric motility like gastric accommodation reflex and gastric emptying rate after the oral administration of acotiamide to FD patients [8]. On the other hand some experiments were performed after the subcutaneous administration of acotiamide to rats to investigate the enhancement of gastric motility by acotiamide in detail because the exposure after the subcutaneous administration of acotiamide is higher than that after the oral administration of acotiamide in rats [9]. These experiments suggested that acotiamide in the stomach tissue might be effective for enhancement of gastric motility as the stomach tissue concentration of acotiamide was 
higher than the $\mathrm{IC}_{50}$ for $\mathrm{AChE}$ after the subcutaneous administration of acotiamide to rats [9]. Since the stomach tissue concentration of acotiamide could be important for the pharmacological action of acotiamide, the distribution of acotiamide to the stomach was evaluated in rats [10]. In that study, acotiamide was highly distributed into the stomach after the intravenous administration of acotiamide to rats [10]. Moreover, the integration plot analysis indicated that acotiamide was uptaken by at least two stomach compartments, which rapidly and slowly equilibrated with the blood [10]. However, as the role of these stomach compartments were unsettled, the relationship of the blood and stomach concentration of acotiamide with the pharmacological action remains unclear.

The purpose of this study was to elucidate the relationship of the blood and stomach concentration of acotiamide with the pharmacological action. For the purpose, we developed a physiologically-based pharmacokinetic and pharmacodynamic $(\mathrm{PBPK} / \mathrm{PD})$ model to describe the profiles for concentration of acotiamide and $\mathrm{ACh}$ in rats. In this model, the stomach compartments rapidly and slowly equilibrated with the blood were assumed as vascular space and extravascular compartment in rat stomach, respectively. In addition, ACh was chosen as the marker for the pharmacological action of acotiamide because the reported index like the motility index might be improper for the describing the time course change for the pharmacological action of acotiamide. The profiles for blood and stomach concentration of acotiamide were determined to characterize the pharmacokinetic parameters. Moreover, to confirm the elevation of ACh derived from the inhibition of AChE by acotiamide, the inhibitory effect of acotiamide on AChE in vitro and the increase of ACh in the stomach were determined.

\section{MATERIALS AND METHODS}

\section{Chemicals}

N-[2-[bis(1-methylethyl)amino] ethyl]-2-[(2-hydroxy-4,5dimethoxybenzoyl)amino] thiazole-4-carboxamide monohydrochloride trihydrate (acotiamide hydrochloride, Z-338/YM443, Fig. 1) and N-[2-(diisopropylamino)ethyl]-2-[(2,<smiles>COc1cc(O)c(C(=O)Nc2nc(C(=O)NCCN(C(C)C)C(C)C)cs2)cc1OC</smiles>

Fig. I Structure of acotiamide hydrochloride. 4,5-trimethoxybenzoyl)amino]-1,3-thiazole-4-carboxamide (ID951551, an internal standard for the determination of acotiamide) were synthesized in the central research laboratories of Zeria Pharmaceutical Co., Ltd. (Saitama, Japan). 1,1-Dimethyl-4-acetylthiomethylpiperidinium iodide (MATP+) was purchased from Dojindo Laboratories (Kumamoto, Japan). 5,5'Dithiobis-2-nitrobenzoic acid (DTNB), and ( \pm )-sulpiride (an internal standard for the determination of MATP $+-\mathrm{TNB}$ ) were purchased from Sigma-Aldrich Co. LLC (St Louis, MO, USA). Acetylcholine iodide and N-ethylmaleimide (NEM) were purchased from Wako Pure Chemical Industries (Osaka, Japan). Acetylcholine-d9 chloride (an internal standard for the determination of $\mathrm{ACh}$ ) was purchased from Toronto Research Chemicals Inc. (Ontario, Canada). All other chemicals were reagent grade.

\section{Animals}

Male Sprague-Dawley rats (aged 6 to 7 weeks) obtained from Charles River Japan, Inc. (Kanagawa, Japan) were housed under standard controlled environmental conditions at 23. $3^{\circ} \mathrm{C}$ and $55 \pm 20 \%$ humidity, with a 12 -h light/dark cycle (7:00-19:00, light) and food (CRF-1; Oriental Yeast Co., Ltd., Tokyo, Japan) and water available ad libitum. Rats were allowed to acclimate to laboratory conditions for at least 1 week prior to performing the experiments. All animal experiments were approved by the Animal Care and Use Committee of the Central Research Laboratories of Zeria Pharmaceutical Co., Ltd.

\section{Preparation of Stomach Homogenate for In Vitro Study}

Rats were anesthetized with isoflurane and their stomachs immediately excised after blood removal, rinsed with distilled water, weighed, and homogenized in distilled water to form a $50 \%$ (w/v) homogenate. Protein concentrations were determined using the Bio-Rad protein assay kit (Bio-Rad, Hercules, CA, USA).

\section{AChE Activity by Stomach Homogenate}

AChE activity was measured using MATP+ as a substrate $(50 \mu \mathrm{M})$, as previously described [11]. Normally, MATP+ is hydrolyzed by AChE and reacted with DTNB. The release of TNB is generally measured with a spectrophotometer at $412 \mathrm{~nm}$ to determine AChE activity. However, in the present study, background absorbance was extremely high in stomach homogenate $(50 \%[\mathrm{w} / \mathrm{v}])$, which compromised the results. We therefore measured the concentration of the MATP+ and TNB complex (MATP+-TNB), which was the result of MATP+ hydrolysis by AChE, using ultra-performance liquid chromatography (UPLC; Waters, Milford, MA, USA). 
The reaction medium $\left(0.1 \mathrm{M} \mathrm{Na}_{2} \mathrm{HPO}_{4}\right.$ and $0.1 \mathrm{M}$ $\mathrm{NaH}_{2} \mathrm{PO}_{4}$ including $0.5 \%$ Triton X-100, pH8.0) contained $10 \mathrm{mM}$ DTNB and $2 \mathrm{mM}$ NEM. Hydrolysis of MATP+ by AChE was initiated by adding $50 \mu \mathrm{M}$ MATP+ to an incubation medium that included the stomach homogenate after preincubation at $30^{\circ} \mathrm{C}$ for $3 \mathrm{~min}$. At designated times, $1 \mathrm{ml}$ of methanol containing $0.1 \%$ formic acid was added to terminate the reaction, and an internal standard $([ \pm]$-sulpiride) was then added. Following centrifugation, the supernatant was evaporated until dry under nitrogen gas in a water bath at $60^{\circ} \mathrm{C}$ and the residue was dissolved in $200 \mu \mathrm{l}$ of mobile phase $\mathrm{B}$ (see below for composition). The concentration of MATP+ -TNB in each sample was determined by UPLC using a hydrophilic interaction chromatography (HILIC) column (ACQUITY UPLC BEH HILIC; Waters) with MATP+ as the standard. Ultraviolet absorbance was monitored at $230 \mathrm{~nm}$. Mobile phase A consisted of methanol and $5 \mathrm{mM}$ ammonium acetate (pH5.0) (50:50). Mobile phase B consisted of acetonitrile, isopropanol and $5 \mathrm{mM}$ ammonium acetate (pH5.0) (90:5:5). A steady gradient started at 1\% mobile phase A for $5 \mathrm{~min}$ at a flow rate of $1.0 \mathrm{ml} / \mathrm{min}$, moving then to $50 \%$ mobile phase $\mathrm{B}$ over the next $4 \mathrm{~min}$, and finally to $1 \%$ mobile phase $\mathrm{A}$ from 9 to $12 \mathrm{~min}$.

The initial hydrolysis velocity was calculated using linear regression of the data taken at $60 \mathrm{~s}$. The effect of acotiamide on the MATP+ hydrolysis was studied at acotiamide concentrations ranging from 0.05 to $25 \mu \mathrm{M}$.

\section{In Vivo Study}

For the intravenous administration of acotiamide, rats were first anesthetized with isoflurane. Acotiamide was dissolved in a 5\% glucose solution and then injected to 66 rats in six different experiments via the femoral vein at $1.85 \mu \mathrm{mol} / \mathrm{kg}$. Blood samples were collected from the abdominal aorta at 5, 10, 15, and $30 \mathrm{~min}$ and 1, 2, 4, 6, 8, 24 and $48 \mathrm{~h}$ after drug administration and then centrifuged to separate the plasma. In addition, at each time point, the stomach was immediately excised, rinsed with distilled water, weighed, and homogenized in distilled water to form a $50 \%(\mathrm{w} / \mathrm{v})$ homogenate. A portion of the homogenate from $5 \mathrm{~min}$ to $4 \mathrm{~h}$ was set aside for the determination of $\mathrm{ACh}$, and the remainder was used for the determination of acotiamide concentration. The concentrations of acotiamide in plasma and stomach tissue and of ACh in stomach tissue were determined via liquid chromatography-mass spectrometry (LC-MS/MS) as described below.

\section{Quantification of Acotiamide by LC-MS/MS}

For the quantification of acotiamide, $250 \mu \mathrm{l}$ of each plasma sample was mixed with $10 \mu \mathrm{l}$ of $50 \%$ methanol, $250 \mu \mathrm{l}$ of $2 \%$ trichloroacetate, and an internal standard. The mixtures were applied to an Oasis HLB $\mu$ Elution solid-phase extraction plate
(Waters), and analytes were eluted with $100 \mu \mathrm{l}$ of methanol. Distilled water $(100 \mu \mathrm{l})$ was added to each elute, and $10-\mu \mathrm{l}$ aliquots were then subjected to LC-MS/MS.

For the stomach tissue, the stomach homogenate was further diluted with the same volume of distilled water to the homogenate. Thereafter, $10 \mu \mathrm{l}$ of $50 \%$ methanol and $200 \mu \mathrm{l}$ of $2 \%$ trichloroacetate were added to the solution. Following centrifugation, an internal standard was added to $300 \mu \mathrm{l}$ of supernatant. The solution was applied to an Oasis HLB $\mu$ Elution solidphase extraction plate, and the analytes were eluted with $40 \mu \mathrm{l}$ methanol. Distilled water $(40 \mu \mathrm{l})$ was added to each elute, and 20- $\mu \mathrm{l}$ aliquots were then subjected to LC-MS/MS.

LC-MS/MS analysis was performed on an API 4000 tandem mass spectrometer (ABSciex, Foster City, CA, USA) equipped with a solvent delivery system (LC-30 AD) and auto-injector (SIL-30 AC; both from Shimadzu, Kyoto, Japan) using a reverse phase column (CAPCELL PAK $\mathrm{C}_{18}$ MGII; Shiseido, Tokyo, Japan). Electrospray ionization was performed in the positive-ion mode. Acotiamide and an internal standard were quantified using the selected reactionmonitoring mode with a flow rate of $0.8 \mathrm{ml} / \mathrm{min}$ methanol/ $20 \mathrm{mM}$ ammonium acetate (pH6.0) (6:4). The monitoring ions for acotiamide and the internal standard were $\mathrm{m} / \mathrm{z}$ $451 \rightarrow m / z 271$ and $m / z 465 \rightarrow m / z 364$, respectively.

\section{Quantification of ACh by LC-MS/MS}

For the quantification of $\mathrm{ACh}, 20 \mu \mathrm{l}$ of stomach homogenate sample was mixed with $100 \mu \mathrm{l}$ of acetonitrile, and $10 \mu \mathrm{l}$ of internal standard was then added to the resulting solution. After centrifugation for $10 \mathrm{~min}(16,000 \times \mathrm{g})$, the supernatant was collected and subjected to LC-MS/MS.

LC-MS/MS analysis was performed on an API 4000 tandem mass spectrometer with a solvent delivery system (LC$30 \mathrm{AD}$ ) and auto-injector (SIL-30 AC) using a HILIC column (Atlantis HILIC; Waters). Electrospray ionization was performed in positive-ion mode. ACh and an internal standard were quantified using the selected reaction-monitoring mode at a flow rate of $0.3 \mathrm{ml} / \mathrm{min}$ acetonitrile $/ 10 \mathrm{mM}$ ammonium formate $(\mathrm{pH}$ 3.0) (65:35). The monitoring ions for ACh and the internal standard were $m / z 146 \rightarrow m / z 87$ and $m / z 155 \rightarrow$ $m / z 87$, respectively.

\section{PBPK/PD Model}

All plasma concentration data were converted to blood concentration data using Eq. 1, as follows:

$C_{a}=C_{p} \cdot R_{b p}$

where $\mathrm{C}_{\mathrm{a}}, \mathrm{C}_{\mathrm{p}}$, and $\mathrm{R}_{\mathrm{bp}}$ denote the arterial blood concentration, plasma concentration, and blood-to-plasma concentration ratio $\left(\mathrm{R}_{\mathrm{bp}}=0.84\right)$, respectively. 
The blood concentrations of acotiamide were fitted to Eq. 2, as follows:

$C_{\mid}=\frac{D \cdot\left(\alpha-k_{2}\right)}{V_{\mathrm{I}} \cdot(\alpha-\beta)} \cdot e^{-\alpha \cdot t}+\frac{D \cdot\left(k_{2}-\beta\right)}{V_{\mathrm{I}} \cdot(\alpha-\beta)} \cdot e^{-\beta \cdot t}$

The tissue concentrations of acotiamide were analyzed by the model shown in Fig. 2. The mass balance equations of each compartment are as follows:

Vascular space:

$V e \cdot \frac{d C_{e}}{d t}=Q_{t} \cdot\left(C_{1}-C_{e}\right)-f_{b} \cdot P S_{\mathrm{inf}} \cdot C_{e}+f_{u} \cdot P S_{e f f} \cdot C_{T}$

Precursor pool:

$$
\begin{aligned}
V_{T} \cdot \frac{d C_{T}}{d t}= & f_{b} \cdot P S_{\mathrm{inf}} \cdot C_{e} \\
& +V_{d} \cdot C_{d} \cdot k_{d i s}-f_{u} \cdot P S_{e f f} \cdot C_{T}-V_{T} \cdot C_{T} \cdot k_{a s s}
\end{aligned}
$$

Deep pool:

$V_{d} \cdot \frac{d C_{d}}{d t}=V_{T} \cdot C_{T} \cdot k_{a s s}-V_{d} \cdot C_{d} \cdot k_{\text {ass }}$

$\mathrm{V}_{\mathrm{d}}, \mathrm{V}_{\text {stomach }}$ and $\mathrm{G}_{\text {stomach }}$ are defined by the following equations:

$$
\begin{aligned}
& V_{d}=V_{T} \cdot \frac{k_{\text {ass }}}{k_{d i s}} \\
& V_{\text {stomach }}=V_{T}+V_{d}
\end{aligned}
$$

$C_{\text {stomach }}=\frac{A_{T}+A_{d}}{V_{\text {stomach }}}$

where $\mathrm{A}_{\mathrm{T}}$ and $\mathrm{A}_{\mathrm{d}}$ denote the amounts of acotiamide in the precursor and deep pools, respectively; $\mathrm{C}_{1}, \mathrm{C}_{\mathrm{e}}, \mathrm{C}_{\mathrm{T}}$, and $\mathrm{C}_{\mathrm{d}}$ denote the acotiamide concentrations in the arterial blood, vascular space, precursor pool, and deep pool, respectively; and $V_{e}, V_{T}$, and $V_{d}$ denote the volumes of the vascular space, precursor pool, and deep pool, respectively. Qt and $\mathrm{V}_{\text {stomach }}$ represent blood flow rate and stomach tissue volume, respectively. $\mathrm{f}_{\mathrm{b}} \cdot \mathrm{PS}_{\mathrm{inf}}$ and $\mathrm{f}_{\mathrm{u}} \cdot \mathrm{PS}_{\mathrm{eff}}$ are the permeation clearances for the influx and efflux of acotiamide between the vascular space and precursor pool, respectively. The deep pool operates under linear conditions and can be characterized by first-order rate constants $\left(\mathrm{k}_{\mathrm{ass}}\right.$ and $\left.\mathrm{k}_{\mathrm{dis}}\right)$. $\mathrm{V}_{\mathrm{e}}$ can be described as the product of $\mathrm{V}_{\mathrm{i}}$ and tissue weight [12]. Data fitting of the model equations was performed using the Phoenix model of the WinNonlin version 6.1 (Pharsight Corp., Mountain View, CA, USA).

ACh concentration in the stomach was simulated using the following model. A pharmacodynamic (PD) model was used as Model 2 [13, 14], and integrated into the PBPK model to estimate the stomach distribution of ACh. According to Model 2, the rate of change in drug response can be described as follows:

$\frac{d R}{d t}=k_{\text {in }}-k_{\text {out }} \cdot\left(1-\frac{C_{T}}{I C_{50}+C_{T}}\right) \cdot R$

where $\mathrm{k}_{\mathrm{in}}$ is the zero-order constant for the production of $\mathrm{ACh}$, and $\mathrm{k}_{\text {out }}$ defines the first-order rate constant of

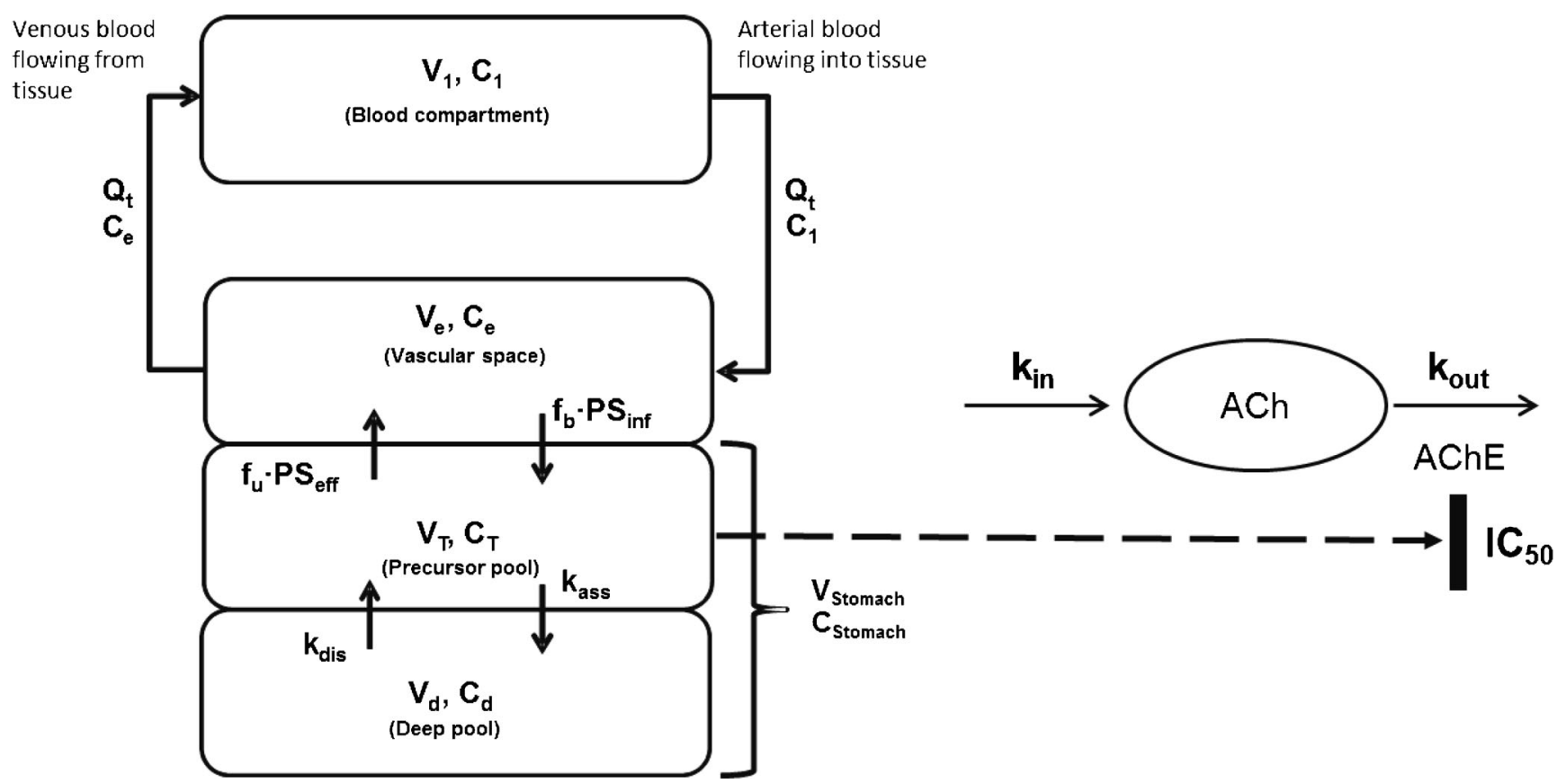

Fig. 2 Physiologically-based pharmacokinetic and pharmacodynamic model to describe the distribution of acotiamide and AChE inhibition in rat stomach following intravenous administration. All terms and mass balance for the model are described in "Materials and Methods". 
hydrolysis of ACh by AChE. R is the observed concentration of $\mathrm{ACh}$, and $\mathrm{IC}_{50}$ is the acotiamide concentration that produces $50 \%$ maximal effect. Data fitting of the model equations was performed using the Phoenix model of the WinNonlin version 6.1.

\section{RESULTS}

\section{PBPK Modeling}

Upon modeling of the disposition of acotiamide in rats, the blood and stomach concentrations of acotiamide were determined after the intravenous administration of acotiamide to rats (Fig. 3). The gastric concentration of acotiamide in the first two sampling point was approximately equal, suggesting the involvement of the time-consuming process in the distribution of acotiamide into the stomach. The assumption was supported by the result of integration plot analysis in our previous report, which showed that the distribution of acotiamide in the stomach consisted of both rapid and slow equilibrium with the blood [10]. We therefore assumed that the vascular space was involved in rapid equilibrium with the blood and the extravascular compartment was involved in slow equilibrium with the blood (Fig. 2). Moreover, the blood-flow independent membrane permeability clearance $\left(\mathrm{f}_{\mathrm{b}} \cdot \mathrm{PS}_{\mathrm{inf}}\right)$ reported in our previous report [10], which suggested that carrier

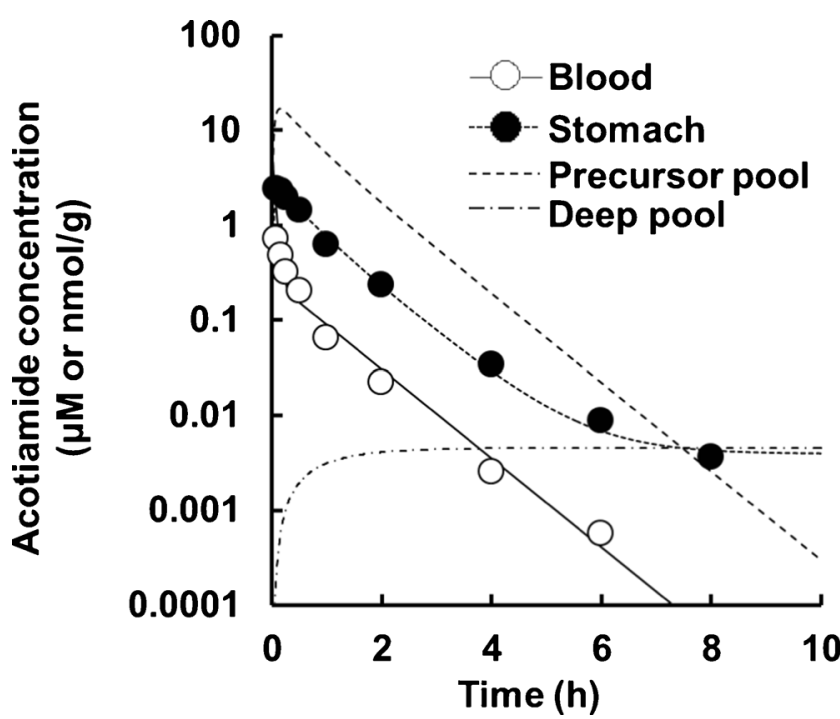

Fig. 3 Profiles and model simulations of acotiamide concentrations in the blood, stomach, precursor pool, and deep pool after intravenous administration to rats. Each point and vertical bar represents the mean \pm S.E. of six rats. All values of S.E. are inside the symbols. Open and closed circles indicate blood concentration and stomach concentration, respectively. Solid, dotted, dashed, and dashed-dotted lines represent the time course of acotiamide concentration in the blood, stomach, precursor pool, and deep pool, respectively. Symbols represent experimentally observed concentrations; lines are simulated concentration profiles using the PBPK model from Fig. 2. mediated uptake process was involved in the distribution of acotiamide to the stomach, was applied to the distribution process of acotiamide into the stomach. After the distribution process, acotiamide was eliminated from the blood and stomach in a biexponential manner (Fig. 3). Acotiamide in the stomach was slowly eliminated compared with the blood compartment (Fig. 3). We assumed the precursor pool where acotiamide is unbound and the deep pool where acotiamide nonspecifically interacts with cellular components (Fig. 2). Overall, acotiamide is first distributed into the vascular space, and subsequently transported from the vascular space to the precursor pool in our PBPK model.

\section{Analysis of Blood and Stomach Concentrations of Acotiamide}

The blood and stomach concentrations were fitted to a PBPK model describing the time course of acotiamide concentration in the blood and stomach (Fig. 3). The concentration of acotiamide in the precursor pool of stomach decreased to approximately $2 \mu \mathrm{M}$ at $2 \mathrm{~h}$ after administration. The concentration of acotiamide in the deep pool of stomach was estimated below $0.01 \mu \mathrm{M}$ after the administration of acotiamide. The terminal phase for the stomach concentration was well fitted by the deep pool of stomach. The kinetic parameters for acotiamide are summarized in Table I. The fitting quality or suitability of the PBPK model was assessed using the maximized log-likelihood function (Loglik) and Akaike's information criterion (AIC), which indicated that the developed PBPK model is appropriate for describing the kinetics of acotiamide (Fig. 3 and Table II).

\section{Inhibition of the Hydrolysis of MATP+ by Acotiamide}

The effect of acotiamide on AChE derived from rat stomach is shown in Fig. 4. The hydrolysis velocity of MATP+ decreased with increasing acotiamide concentration, with an $\mathrm{IC}_{50}$ value of $1.79 \mu \mathrm{M}$ (Table I).

\section{PD Modeling}

The indirect response model was linked with the PBPK model for describing the inhibition of AChE by acotiamide. The concentration of acotiamide used in the PD model was chosen as the concentration of acotiamide in the precursor pool of stomach, which covered the $\mathrm{IC}_{50}$ value for the inhibition of AChE by acotiamide.

\section{Analysis of Stomach Concentration of ACh}

The profile of ACh after the administration of acotiamide is shown in Fig. 5. The concentration of ACh rose to 131\% $\%$ of baseline) at $2 \mathrm{~h}$ after administration of acotiamide. When 
Table I Physiological and Pharmacokinetic Parameters for PBPK Analysis in Rats

\begin{tabular}{|c|c|c|}
\hline Parameter & Value & Source \\
\hline$V_{1}(\mathrm{~m} / \mathrm{kg})$ & 302 & By fitting \\
\hline$k_{1}\left(\min ^{-1}\right)$ & 0.126 & By fitting \\
\hline $\mathrm{k}_{2}\left(\min ^{-1}\right)$ & 0.0313 & By fitting \\
\hline $\mathrm{CL}_{\text {tot }}(\mathrm{ml} / \mathrm{min} / \mathrm{kg})$ & 56.9 & By fitting \\
\hline $\mathrm{V}_{\mathrm{e}}(\mathrm{ml})$ & 0.441 & Calculated from $V_{i}[10]$ and tissue weight [12] \\
\hline $\mathrm{V}_{\text {stomach }}(\mathrm{ml})$ & 1.1 & Hosseini-Yeganeh and McLachlan [12] \\
\hline $\mathrm{f}_{\mathrm{b}} \cdot P S_{\text {inf }}(\mathrm{ml} / \mathrm{min})$ & 0.174 & Yoshii et al., 201। [ [ 0] \\
\hline $\mathrm{Q}_{\mathrm{t}}(\mathrm{ml} / \mathrm{min})$ & 1.1 & Hosseini-Yeganeh and McLachlan [12] \\
\hline $\mathrm{V}_{\mathrm{T}}(\mathrm{ml})$ & 0.133 & By fitting \\
\hline$f_{u} \cdot P S_{\text {eff }}(\mathrm{ml} / \mathrm{min})$ & 0.00600 & By fitting \\
\hline$k_{\text {ass }}\left(\min ^{-1}\right)$ & 0.0000320 & By fitting \\
\hline$k_{\text {dis }}\left(\min ^{-1}\right)$ & 0.00000485 & By fitting \\
\hline $\mathrm{IC}_{50}(\mu \mathrm{M})$ & 1.79 & In vitro study \\
\hline $\mathrm{k}_{\text {in }}(\mathrm{nmol} / \mathrm{g}$ of tissue/min) & 0.00314 & By fitting \\
\hline $\mathrm{k}_{\text {out }}\left(\min ^{-1}\right)$ & 0.00415 & By fitting \\
\hline
\end{tabular}

the data of ACh concentrations was fitted to our PBPK/PD model without fixing the PD parameters $\left(\mathrm{k}_{\mathrm{in}}, \mathrm{k}_{\mathrm{out}}\right.$ and $\left.\mathrm{IC}_{50}\right)$, $\mathrm{k}_{\mathrm{in}}, \mathrm{k}_{\text {out }}$ and $\mathrm{IC}_{50}$ were $0.00337 \mathrm{nmol} / \mathrm{g}$ of tissue $/ \mathrm{min}$, $0.00446 \mathrm{~min}^{-1}$ and $2.10 \mu \mathrm{M}$, respectively. At that fitting, Loglik and AIC were 43.9 and -75.8 , respectively, which indicated that the PBPK/PD model is appropriate for describing the kinetics of ACh. When the data of ACh concentrations was fitted to our model with fixing $\mathrm{IC}_{50}(1.79 \mu \mathrm{M})$, the profile of stomach concentration of $\mathrm{ACh}$ was well estimated by the PBPK/PD model on the assumption that acotiamide in the precursor pool of stomach inhibited AChE (Fig. 5).

\section{DISCUSSION}

The stomach concentration of acotiamide was higher than the blood concentration in the first time point when acotiamide concentration was measured after intravenous administration of acotiamide to rats. Acotiamide was slowly eliminated in the stomach compared to the blood. Our PBPK model well described the profile of acotiamide concentration in the blood and stomach in the assumption that acotiamide was rapidly distributed into the vascular space, uptaken to the precursor pool of stomach by carrier mediated process and permeated in the deep pool of stomach. ACh, which was determined as the

Table II Fitting Quality of the PBPK Model for the

Time Course of Acotiamide Concentrations in Blood and Stomach

\begin{tabular}{ll}
\hline Loglik & AIC \\
\hline 36.0 & -61.9
\end{tabular}

Loglik, maximized log-likelihood function; AIC Akaike's information criterion

Calculated using number of observations $=$ 26 and number of parameters $=5$ marker of the involvement of acotiamide in inhibiting AChE, reached the maximum concentration in the stomach at $2 \mathrm{~h}$ after intravenous administration of acotiamide, while the stomach concentration of acotiamide peaked at $0.0833 \mathrm{~h}$, indicating the existence of time lag between the stomach concentration of acotiamide and ACh. The unbound concentration of acotiamide in the precursor pool was higher than the in vitro $\mathrm{IC}_{50}$ value of acotiamide for inhibiting AChE activity by approximately $2 \mathrm{~h}$ after administration of acotiamide. The PD model well described the profile of ACh concentration in the stomach in the assumption that the unbound concentration of acotiamide in the precursor pool inhibited AChE with

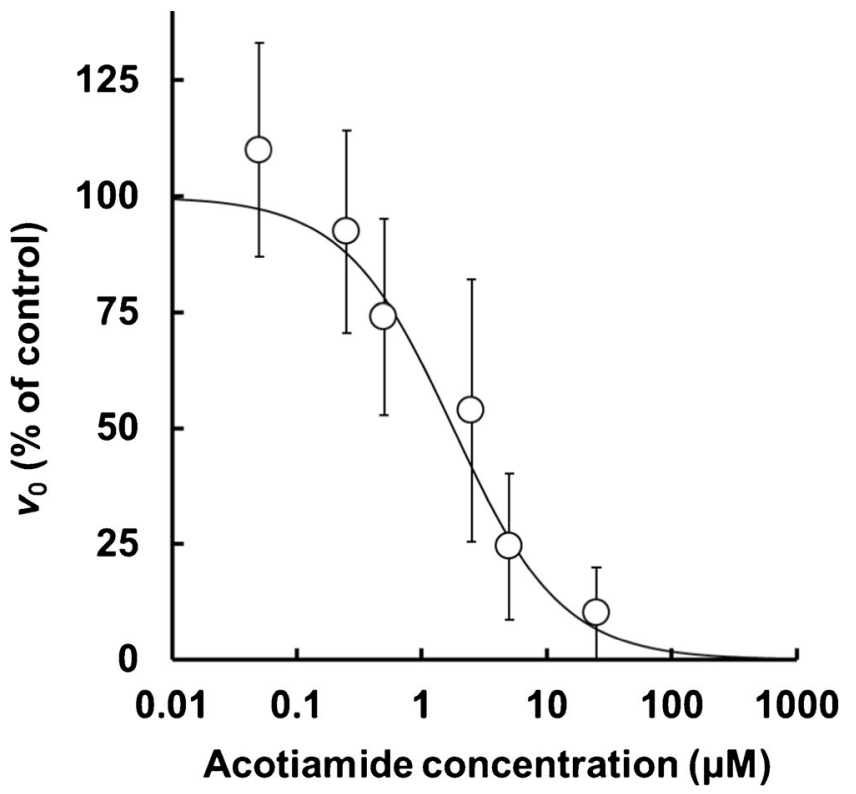

Fig. 4 Inhibition of MATP+ hydrolysis by acotiamide. Each point and vertical bar showing the hydrolysis velocity $\left(v_{0}\right)$ of MATP + represents the mean $\pm S . E$. for three determinations. 


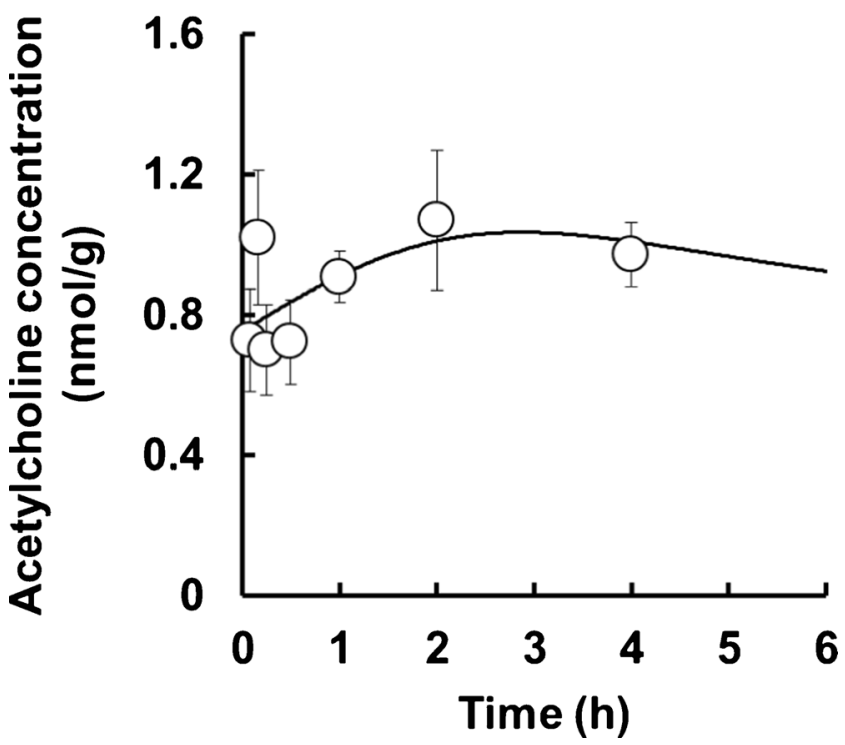

Fig. 5 Profile and model simulation of ACh concentration in the stomach homogenate after intravenous administration of acotiamide to rats. Each point and vertical bar represents the mean \pm S.E. of six rats. Symbols represent experimentally observed concentrations, while curves show the simulated concentration profiles from the PBPK/PD model (Fig. 2).

the in vitro $\mathrm{IC}_{50}$ for $\mathrm{AChE}$ inhibition. These results suggested that acotiamide inhibited AChE in the precursor pool of stomach where acotiamide was distributed by carrier mediated process.

To our knowledge, no reports have been published on a PK model for the distribution of drugs from blood to stomach as the pharmacological target although some reports have been reported on a PK model containing stomach as delivery organ of drugs to small intestine [15-17]. The precursor and deep pool of stomach were put in our model to describe the rate-limiting step in the uptake of acotiamide by stomach and slower elimination of acotiamide from stomach than blood. Acotiamide in the precursor pool of stomach plays an important role in the elevation of ACh in the stomach though the anatomical meanings of these compartments remain unclear. It's normally difficult to estimate the microenvironmental concentration of drugs in tissue. For brain, microdialysis method was applied to estimate the unbound concentration of drugs penetrating into brain $[18,19]$. The method for prediction of the unbound concentration of drugs in brain was also reported by Fridén et al. [20]. For stomach, the application of microdialysis to submucosa which is thicker than muscular layer and unrelated with gastric motility in the gastric layers was only reported [21, 22]. Moreover, there is no report concerning the method for prediction of the unbound concentration of drugs in stomach. Thus, we proposed a mechanism based PK model to estimate the concentration of drugs exerting their pharmacological effects in tissues like gastroprokinetic agents in stomach.

The selectivity of drug to its target is achieved by the specific affinity to drug targets, the selective access to site where drug targets exist, and/or the unique localization of drug target. For example, histamine $\mathrm{H} 2$ receptor, which is only involved in the regulation of gastric acid secretion among four subtypes of histamine $\mathrm{H}$ receptor, is a selective target for the suppressor of gastric acid secretion [23, 24]. L-type amino acid transporter 1 is consider as a specific target for antitumor because L-type amino acid transporter 1, transporting amino acids needed for the growth of cancer cells, selectively expresses in cancer cells $[25,26]$. AChE, the target of acotiamide is a ubiquitous enzyme. In addition, ACh which is regulated by AChE interacts with each subtype of muscarinic receptor. There might be no selectivity on the pathway from the contact of acotiamide with AChE to the evoking of pharmacological action, so the selectivity of acotiamide to its target might be derived only from the feature in the distribution of acotiamide. Thus, it's seems important to put in the distribution parameters to stomach in the development of our PBPK/ PD model. $\mathrm{f}_{\mathrm{b}} \cdot \mathrm{PS}_{\mathrm{inf}}$ of the distribution parameters was calculated from the uptake clearance of acotiamide to stomach [10]. The uptake clearance can be expressed as the slope in the integration plot, where stomach to blood concentration ratio is plotted against area under the blood concentration curve to blood concentration ratio when the uptake of acotiamide was determined in a short time, during which the efflux and/or elimination of acotiamide from stomach were negligible. $\mathrm{V}_{\mathrm{e}}$ of the distribution parameters $(0.401 \mathrm{ml} /$ $\mathrm{g}$ of tissue) was calculated as the product of the intercept $\left(\mathrm{V}_{\mathrm{i}}\right)$ of $\mathrm{y}$ axis of integration plot and tissue weight $\left(\mathrm{V}_{\mathrm{i}} \cdot\right.$ tissue weight $)$. When $\mathrm{V}_{\mathrm{e}}$ was compared with the volume of capillary bed $(0.0108 \mathrm{ml} / \mathrm{g}$ of tissue) [27] and inulin space $(0.295 \mathrm{ml} / \mathrm{g}$ of tissue) [10], $\mathrm{V}_{\mathrm{e}}$ was similar to inulin space, an extracellular space. Therefore, $\mathrm{f}_{\mathrm{b}} \cdot \mathrm{PS}_{\mathrm{inf}}$ might represent the transport of acotiamide through plasma membrane of gastric cells. Moreover, the volume of precursor pool $\left(\mathrm{V}_{\mathrm{T}}\right)$ which was $12.1 \%$ of the volume of stomach $\left(\mathrm{V}_{\text {stomach }}\right)$ was similar to fraction of acotiamide distributed to the stomach cytosol $(12.0 \%)$ reported in our previous report [10]. The result suggested that the volume of precursor and deep pool reflected fraction of acotiamide distributed to cytosol and organelle of gastric cells, respectively.

The time lag between drug concentration and the effect was often observed [13, 14, 28]. For describing the delay of drug effect, the PD models like hypothetical effect compartment model and indirect response model were used. The hypothetical effect compartment model is useful in the case that mechanism of the delay for drug effect is unknown, while the indirect response model is available for drugs whose mechanism of the delay is derived from the mechanism of action. An indirect response model was chosen as our PD model because acotiamide is a known AChE inhibitor. Dayneka et al. classified the indirect response model into four models types-based on the mechanism of action [13]. Based on this classification, the effects of reversible anticholinesterase agents, which inhibit 
the enzymatic breakdown of ACh, demonstrated that our model could be categorized as Model 2. The rate of change in drug response using this model is described by Eq. 9, and many drugs described in this manner show a delay compared to the time course of the drug concentration. Jusko et al. used an indirect response model to describe the muscular response as ACh level in patients with myasthenia gravis during therapy using pyridostigmine, acetylcholinesterase inhibitor [29]. Therefore, the indirect response model is suitable for describing the inhibitory effect of acotiamide on AChE in rat stomach.

Normally, acetylthiocholine (ATCh) is used to evaluate AChE activity [30]. However, ATCh is a known substrate of both AChE and butyrylcholinesterase (BChE), meaning BChE inhibitors such as iso-OMPA need to be included in the incubation medium when investigating acotiamide effects [31]. Recently, Kikuchi et al. reported that MATP+ was suitable AChE selective substrates for detecting of AChE activity [11]. Therefore, in this study, we used MATP+ as substrate of AChE for investigation of the effects of acotiamide on the AChE activity. Hydrolysis velocity of MATP+ was decreased by the addition of acotiamide, with the $\mathrm{IC}_{50}$ value of $1.79 \mu \mathrm{M}$. Kawachi et al. have reported that acotiamide inhibited ATCh hydrolysis by stomach homogenate with $\mathrm{IC}_{50}$ value of $2.3 \mu \mathrm{M}$ [9]. Furthermore, acotiamide also inhibited human AChE with $\mathrm{Ki}$ value of $0.61 \mu \mathrm{M}$ [31]. Our observation was similar to these previously results, therefore, it was considered that using of MATP+ for investigation of AChE inhibition is appropriate.

In conclusion, we elucidated the relationship of the blood and stomach concentration of acotiamide with the pharmacological action. Acotiamide was distributed by carrier mediated process and inhibited AChE in the precursor pool of stomach. Acotiamide in the precursor pool plays an important role for producing the pharmacologic action. Moreover, we proposed $\mathrm{PBPK} / \mathrm{PD}$ model to describe the pharmacologic action of acotiamide in stomach.

Open Access This article is distributed under the terms of the Creative Commons Attribution 4.0 International License (http://creativecommons.org/licenses/by/4.0/), which permits unrestricted use, distribution, and reproduction in any medium, provided you give appropriate credit to the original author(s) and the source, provide a link to the Creative Commons license, and indicate if changes were made.

\section{REFERENCES}

1. Talley NJ, Axon A, Bytzer P, Holtmann G, Lam SK, Van Zanten S. Management of uninvestigated and functional dyspepsia: a working party report for the world congresses of gastroenterology 1998. Aliment Pharmacol Ther. 1999;13: $1135-48$.

2. Tack J, Masaoka T, Janssen P. Functional dyspepsia. Curr Opin Gastroenterol. 201 1;27:549-57.

3. Mizuta Y, Shikuwa S, Isomoto H, Mishima R, Akazawa Y, Masuda $\mathrm{J}$, et al. Recent insights into digestive motility in functional dyspepsia. J Gastroenterol. 2006;41:1025-40.

4. Tack J. Prokinetics and fundic relaxants in upper functional GI disorders. Curr Opin Pharmacol. 2008;8:690-6.

5. Matsueda K, Hongo M, Tack J, Saito Y, Kato H. A placebocontrolled trial of acotiamide for meal-related symptoms of functional dyspepsia. Gut. 2012;61:821-8.

6. Nolan ML, Scott LJ. Acotiamide: first global approval. Drugs. 2013;73:1377-83.

7. Sun Y, Song G, McCallum RW. Evaluation of acotiamide for the treatment of functional dyspepsia. Expert Opin Drug Metab Toxicol. 2014;10:1161-8.

8. Kusunoki H, Haruma K, Manabe N, Imamura H, Kamada T, Shiotani A, et al. Therapeutic efficacy of acotiamide in patients with functional dyspepsia based on enhanced postprandial gastric accommodation and emptying: randomized controlled study evaluation by real-time ultrasonography. Neurogastroenterol Motil. 2012;24:540-5.

9. Kawachi M, Matsunaga Y, Tanaka T, Hori Y, Ito K, Nagahama $\mathrm{K}$, et al. Acotiamide hydrochloride (Z-338) enhances gastric motility and emptying by inhibiting acetylcholinesterase activity in rats. Eur J Pharmacol. 201 1;666:218-25.

10. Yoshii K, Hirayama M, Nakamura T, Toda R, Hasegawa J, Takei $\mathrm{M}$, et al. Mechanism for distribution of acotiamide, a novel gastroprokinetic agent for the treatment of functional dyspepsia, in rat stomach. J Pharm Sci. 201 1;100:4965-73.

11. Kikuchi T, Okamura T, Fukushi K, Irie T. Piperidine-4methanthiol ester derivatives for a selective acetylcholinesterase assay. Biol Pharm Bull. 2010;33:702-6.

12. Hosseini-Yeganeh M, McLachlan AJ. Physiologically-based pharmacokinetic model for terbinafine in rats and humans. Antimicrob Agents Chemother. 2002;46:2219-28.

13. Dayneka NL, Garg V, Jusko WJ. Comparison of four basic models of indirect pharmacodynamic responses. J Pharmacokinet Biopharm. 1993;21:457-78.

14. Felmlee MA, Morris ME, Mager DE. Mechanism-based pharmacodynamic modeling. Methods MolBiol. 2012;929:583-600.

15. Agoram B, Woltosz WS, Bolger MB. Predicting the impact of physiological and biochemical processes on oral drug bioavailability. Adv Drug Deliv Rev. 2001;50:S41-67.

16. Fenneteau F, Poulin P, Nekka F. Physiologically based predictions of the impact of inhibition of intestinal and hepatic metabolism on human pharmacokinetics of CYP3A substrates. J Pharm Sci. 2010;99:486-514

17. Poulin P, Jones RD, Jones HM, Gibson CR, Rowland M, Chien JY, et al. PHRMA CPCDC initiative on predictive models of human pharmacokinetics, part 5: prediction of plasma concentrationtime profiles in human by using the physiologically-based pharmacokinetic modeling approach. J Pharm Sci. 2011;100:4127-57.

18. Chen X, Loryan I, Payan M, Keep RF, Smith DE, HammarlundUdenaes M. Effect of transporter inhibition on the distribution of cefadroxil in rat brain. Fluids Barriers CNS. 2014;1 1:25.

19. Sadiq MW, Boström E, Keizer R, Björkman S, HammarlundUdenaes M. Oxymorphone active uptake at the blood-brain barrier and population modeling of its pharmacokineticpharmacodynamic relationship. J Pharm Sci. 2013;102:3320-31.

20. Fridén M, Gupta A, Antonsson M, Bredberg U, HammarlundUdenaes M. In vitro methods for estimating unbound drug concentrations in the brain interstitial and intracellular fluids. Drug Metab Dispos. 2007;35:1711-9. 
21. Ericsson P, Håkanson R, Norlén P. Gastrin response to candidate messengers in intact conscious rats monitored by antrum microdialysis. Regul Pept. 2010;163:24-30.

22. Cibicek N, Zivna H, Vrublova E, Cibicek J, Cermakova E, Palicka V. Gastric submucosal microdialysis in the detection of rat stomach ischemia-a comparison of the ${ }^{3} \mathrm{H}_{2} \mathrm{O}$ efflux technique with metabolic monitoring. Physiol Meas. 2010;31:1355-68.

23. Lin TM, Evans DC, Warrick MW, Pioch RP. Actions of nizatidine, a selective histamine H2-receptor antagonist, on gastric acid secretion in dogs, rats and frogs. J Pharmacol Exp Ther. 1986;239:40610 .

24. Schubert ML, Peura DA. Control of gastric acid secretion in health and disease. Gastroenterology. 2008;134:1842-60.

25. Kanai Y, Segawa H, Miyamoto K, Uchino H, Takeda E, Endou H. Expression cloning and characterization of a transporter for large neutral amino acids activated by the heavy chain of 4F2 antigen (CD98). J Biol Chem. 1998;273:23629-32.

26. Wang Q, Bailey CG, Ng C, Tiffen J, Thoeng A, Minhas V, et al. Androgen receptor and nutrient signaling pathways coordinate the demand for increased amino acid transport during prostate cancer progression. Cancer Res. 2011;71:7525-36.

27. Bernareggi A, Rowland M. Physiologic modeling of cyclosporin kinetics in rat and man. J Pharmacokinet Biopharm. 1991;19:2150 .

28. Ito Y, Harada T, Fushimi K, Kagawa Y, Oka H, Nakazawa H, et al. Pharmacokinetic and pharmacodynamic analysis of acetylcholinesterase inhibition by distigmine bromide in rats. Drug Metab Pharmacokinet. 2010;25:254-61.

29. Jusko WJ, Ko HC. Physiologic indirect response models characterize diverse types of pharmacodynamic effects. Clin Pharmacol Ther. 1994;56:406-19.

30. Ellman GL, Courtney KD, Andres Jr V, Feather-Stone RM. A new and rapid colorimetric determination of acetylcholinesterase activity. Biochem Pharmacol. 1961;7:88-95.

31. Matsunaga Y, Tanaka T, Yoshinaga K, Ueki S, Hori Y, Eta R, et al. Acotiamide hydrochloride (Z-338), a new selective acetylcholinesterase inhibitor, enhances gastric motility without prolonging QT interval in dogs: comparison with cisapride, itopride, and mosapride. J Pharmacol Exp Ther. 201 1;336:791-800. 